\title{
PENGARUH FASILITAS TERHADAP KEPUASAN PENGUNJUNG PADA HAIROS WATER PARK \\ MEDAN
}

\author{
Siti Rahmah, Wahyu Sri Haryani, Teguh Satya Wira \\ Alumni Sekolah Tinggi Ilmu Manajemen Sukma \\ Program studi Manajemen, Sekolah Tinggi Ilmu Manajemen \\ wahyusriharyani@gmail.com, teguhsatyaw@gmail.com
}

\begin{abstract}
The purpose of this research is to how much facility effect to satisfaction at Hairos Water Park Medan. The sample are 99 people, using random sampling is that provides an equal opportunity for every member of the population to be sample. Data analysis using simple regression test, hypotesis testing the coefficient of determination $\left(R^{2}\right)$, and partial test (t test). Data processing using SPSS 20. The rulest showed that the partial facilities have no effect and not significant to visitor satisfaction at Hairos Water park.
\end{abstract}

Keyword: Facility and Satisfaction

\section{PENDAHULUAN}

Pariwisata merupakan bagian dari sector industri di Indonesia yang prospeknya cerah, dan mempunyai potensi serta peluang yang sangat besar untuk dikembangkan dan memberikan keuntungan yang besar, salah satunya objek wisata. Objek wisata adalah suatu bentukan atau aktivitas dan fasilitas yang berhubungan, yang dapat menarik minat wisatawan atau pengunjung untuk datang serta mendapatkan kepuasan pada suatu daerah atau tempat tertentu. banyak hal yang harus diperhatikan dalam mengembangkan suatu objek wisata, yaitu dengan memberikan sesuatu yang sesuai dengan kebutuhan dan keinginan calon pengunjung. Banyal hal yang dapat mempengaruhi kepuasan pengunjung terhadap pelayanan yang diberikan, seperti fasilitas. Fasilitas merupakan salah satu indikator dalam menetukan sesuatu yang ingin dipilih. Fasilitas yang baik dapat memberikan kepuasan yang baik bagi pengunjung.

Penelitian yang dilakukan oleh Amaliawati (2015) menyatakan bahwa fasilitas berpengaruh positif terhadap kepuasan pengunjung objek wisata Umbul Penggin Surakarta. Penelitian oleh Stevianus (2014) menyatakan bahwa atraksi wisata yang berpengaruh signifikan terhadap kepuasan pengunjung dan variabel lainnya hanya berpengaruh positif dan tidak signifikan terhadap kepuasan pengunjung di Taman Margasatwa Ragunan Jakarta. Penelitian yang dilakukan oleh Sulistiyana et al (2015) menyatakan bahwa fasilitas wisata memiliki pengaruh signifikan terhadap kepuasan konsumen Museum Satwa Malang.

\section{Perumusan Masalah}

Perumusan Masalah Penelitian ini yaitu apakah ada pengaruh fasilitas terhadap kepuasan pengunjung pada Hairos Water Park?

\section{Batasan Masalah}

Penelitian ini dibatasi hanya pada fasilitas yang ada di Hairos Water Park.

\section{Tujuan Penelitian}

Adapun tujuan penelitian ini dilaksanakan adalah untuk mengetahui pengaruh fasilitas terhadap kepuasan pengunjung pada Hairos Water Park.

\section{Manfaat Penelitian}

Hasil penelitian ini diharapkan bermanfaat bagi :

1. Bagi peneliti, menambah pengetahuan dan wawasan peneliti khususnya berkenaan dengan pengaruh fasilitas terhadap kepuasan pengunjung;

2. Pengelola Objek Wisata, sebagai bahan masukan mengenai fasilitas yang berpengaruh terhadap kepuasan pengunjung; 
3. Bagi STIM Sukma, sebagai tambahan hasil penelitian yang dapat diguanakan sebagai rujukan dan dikembangkan lebih lanjut;

4. Bagi Peneliti selanjutnya, sebagai bahan acuan bagi peneliti lain serta sebagai referensi dalam penelitian selanjutnya.

\section{METODE PENELITIAN}

\section{Jenis dan Sumber Data}

1. Data primer adalah sumber data yang secara langsung memberikan data kepada pengumpul data (Sugiyono, 2012:25). Data primer berupa catatan hasil wawacara yang diperoleh melalui wawancara yang penulis lakukan.

2. Data sekunder merupakan sumber data yang tidak memberikan informasi secara langsung kepada pengumpul data. Sumber data sekunder ini data berupa hasil pengolahan lebih lanjut dari data primer yang disajikan dalam bentuk lain (Sugiyono, 2012:25). Data ini digunakan untuk mendukung informasi dari data primer.

Sumber data yang digunakan yaitu:

1. Data internal adalah data yang menggambarkan situasi dan kondisi pada suatu organisasi secara internal. Dalam hal ini meliputi data Hairos Water Park.

2. Data eksternal adalah data yang diambil dari luar tempat dilakukannya penelitian, seperti internet dan perpustakaan.

\section{Populasi dan Sampel}

Populasi adalah wilayah generalisasi yang terdiri dari atas objek/subjek yang mempunyai kualitas dan karakteristik tertentu yang ditetapkan oleh peneliti untuk dipelajari dan kemudian ditarik kesimpulannya (Sugiyono, 2012:115). Populasi yang diambil dalam penelitian adalah seluruh pengunjung dari tahun 2014-2016 berjumlah 9.385 orang.

Sampel menurut Sugiyono (2012:116) adalah "bagian dari jumlah dan karakteristik yang dimiliki oleh populasi tersebut. Teknik sampling yang diguanakn adalah random sampling. Random sampling adalah teknik pengambilan sampel yang memberikan kesempatan yang sama kepada setiap anggota yang ada dalam satu populasi untuk dijadikan sampel. Sampel penelitian ini diambil dengan mengguanakan teknik slovin dengan rumus:

$\mathrm{n}$ : sampel

$$
n=\frac{N}{1+N e^{2}}
$$

$\mathrm{N}$ : Populasi

e : Perkiraan tingkat kesalahan

dengan jumlah populasi 9.385 orang dan perkiraan tingkat kesalahan $10 \%$ maka didapat jumlah sampel sebanyak 99 orang.

\section{Metode Pengumpulan Data}

Metode pengumpulan data yang digunakan dalam penelitian ini sebagai berikut:

1. Studi Dokumentasi: pengumpulan data yang dilakukan dengan mencari informasi berdasarkan dokumen-dokumen perusahaan yang berkaitan dengan penelitian.

2. Kuesioner: metode pengumpulan data dengan membuat daftar pertanyaan dalam bentuk angket yang ditujukan kepada responden yang dijadikan sampel.

3. Observasi: pengamatan data melalui pengamatan secara langsungdi Hairos Water Park.

\section{Definisi Operasional}

Berdasarkan rumusan masalah, maka variabel-variabel dalam penelitian ini dapat diidentifikasi sebagai berikut:

1. Variabel bebas (variabel independen) adalah variabel yang mempengaruhi variabel terikat, yang terdiri dari fasilitas $(\mathrm{X})$;

2. variabel terikat (variabel dependen) adalah variabel yang dipengaruhi oleh variabel bebas, yaitu kepuasan pengunjung (Y). 
Table 1 Operasionalisasi Variabel Penelitian

\begin{tabular}{|c|c|c|c|c|}
\hline No & Variabel & Definisi & Indikator & $\begin{array}{l}\text { Skalau } \\
\text { kur }\end{array}$ \\
\hline 1 & Fasilitas (X) & $\begin{array}{l}\text { Sumber daya fisik yang harus } \\
\text { ada sebelum suatu jasa dapat } \\
\text { ditawarkan kepada konsumen, } \\
\text { fasilitas dapat pula berupa } \\
\text { segala sesuatu yang } \\
\text { memudahkan konsumen dalam } \\
\text { memperoleh kepuasan. }\end{array}$ & $\begin{array}{ll}\text { 1. } & \text { Pertimbangan/perenc } \\
\text { anaan spasial } \\
\text { 2. Perencanaan ruang } \\
\text { 3. Perlengkapan/perabot } \\
\text { an } \\
\text { 4. Tata cahaya dan } \\
\text { warna } \\
\text { 5. Pesan-pesan yang } \\
\text { disampaikan secara } \\
\text { grafis } \\
\text { 6. Unsur pendukung }\end{array}$ & Likert \\
\hline 2 & $\begin{array}{l}\text { Kepuasan } \\
\text { Pengunjung } \\
\text { (Y) }\end{array}$ & $\begin{array}{l}\text { Kepuasan Wisatawan adalah } \\
\text { pengukuran yang dilakukan secara } \\
\text { simultan". }\end{array}$ & $\begin{array}{ll}\text { 1. Kualitas Produk } \\
\text { 2. Kualitas Pelayanan } \\
\text { 3. Emosional } \\
\text { 4. Harga } \\
\text { 5. Kemudahan }\end{array}$ & Likert \\
\hline
\end{tabular}

Sumber : Lumentut dan Palandeng (2014), Utama (2017:204), Tumvila (2015), Rosita et al (2016). Uji Validitas dan Reliabilitas

Menurut Sugiyono (2012:110) "uji validitas adalah suatu langkah pengujian yang dilakukan terhadap isi dari suatu instrumen, dengan tujuan mengukur ketepatan instrument yang digunakan dalam suatu penelitian". Dikatakan valid jika nilai $r_{\text {hitung }} \geq r_{\text {tabel }}$ dan dikatakan tidak valid jika nilai $\mathrm{r}_{\text {hitung }}<\mathrm{r}_{\text {tabel. }}$.

Menurut Sugiyono (2012:111) "uji reliabilitas adalah proses pengukuran terhadap ketepatan (konsiten) dari suatu instrumen". Dikatakan reliabel jika nilai crombac halfa $>0,6$ dan dikatakan tidak reliabel jika nilai crombachalfa $<0,6$.

\section{Metode Analisi Data}

Metode analisis data yang digunakan dalam penelitian ini adalah metode deskriptif kuantitatif, sedangkan model analisis yang digunakan dalam penelitian ini adalah regresi linier sederehana, dengan model persamaan:

$$
\mathrm{Y}=\mathrm{a}+\mathrm{bX}+\mathrm{e}
$$

Dimana:

$$
\begin{array}{ll}
\mathrm{Y} & =\text { Kepuasan pengunjung } \\
\mathrm{X} & =\text { Fasilitas } \\
\mathrm{a} & =\text { Konstanta } \\
\mathrm{b} & =\text { Koefisienregresi variable fasilitas } \\
\mathrm{e} & =\text { Error } \text { of term (variabel yang tidakditeliti) }
\end{array}
$$

\section{Kerangka Berpikir}

Fasilitas adalah sarana untuk melancarkan dan memudahkan pelaksanaan fungsi. Kepuasan adalah fungsi perbedaan antara kinerja yang dirasakan (perceived performance) dengan harapan (expeciations). Penelitian yang dilakukan oleh Mongkaren (2013) menunjukkan bahwa fasilitas dan kualitas pelayanan secara simultan dan parsial berpengaruh signifikan terhadap kepuasan pelanggan. 


\section{Fasilitas \\ Kepuasan pengunjung}

Gambar 1 kerangka Berpikir

Sumber : Mongkaren (2013)

\section{Hipotesis}

Menurut sugiyono (2012:84) hipotesis diartikan sebagai jawaban sementara terhada prumusan masalah penelitian.

Berdasarkan pengertian di atas, maka hipotesis penelitian ini adalah "ada pengaruh fasilitas terhadap kepuasan pengunjung pada Hairos Water Park".

\section{Pengujian Hipotesis}

a. Koefisien Determinasi $\left(\mathrm{R}^{2}\right)$

Koefisien determinasi $\left(\mathrm{R}^{2}\right)$ pada intinya mengukur seberapa besar kemampuan model dalam menerangkan variabel terikat. Semakin besar koefisien determinasi (mendekati satu), maka dapat dikatakan bahwa pengaruh variabel bebas $(\mathrm{X})$ adalah besar terhadap variabel terikat (Y).

b. Koefisien Parsial (Uji t)

Uji parsial (uji t) bertujuan untuk melihat pengaruh fasilitas terhadap kepuasan pengunjung, dengan kriteria:

1. jika $t_{\text {hitung }} \leq t_{\text {tabel }}$, maka $H_{0}$ diterima $H_{1}$ ditolak, artinya secara parsial penelitian tidak berpengaruh.

2. jika $t_{\text {hitung }}>t_{\text {tabel }}$, maka $H_{0}$ ditolak $H_{1}$ diterima, artinya secara parsial dan penelitian berpengaruh atau ada pengaruh.

\section{HASIL DAN PEMBAHASAN}

Deskripsi data variabel Fasilitas

Untuk mengukur fasilitas Hairos Water Park, digunakan 6 indikator sesuai dengan teori yang ada. Berdasarkan pernyataan-pernyataan yang telah dijawab oleh responden, maka dihasilkan data sebagai berikut:

Tabel 1 Rekapitulasi jawaban responden variabel Fasilitas (X)

\begin{tabular}{|c|c|c|c|c|c|c|c|c|c|c|c|c|}
\hline \multirow[t]{2}{*}{ No } & \multirow{2}{*}{ Pernyataan } & \multicolumn{2}{|c|}{ SS } & \multicolumn{2}{|c|}{$\mathrm{S}$} & \multicolumn{2}{|c|}{$\mathrm{CS}$} & \multicolumn{2}{|c|}{ TS } & \multicolumn{2}{|c|}{ STS } & \multirow{2}{*}{ Jlh } \\
\hline & & $\mathrm{F}$ & $\%$ & $\mathrm{~F}$ & $\%$ & $\mathrm{~F}$ & $\%$ & $\mathrm{~F}$ & $\%$ & $\mathrm{~F}$ & $\%$ & \\
\hline 1 & Fasilitas1 & 18 & $18 \%$ & 36 & $36 \%$ & 38 & $38 \%$ & 7 & $7 \%$ & 0 & $0 \%$ & 99 \\
\hline 2 & Fasilitas2 & 17 & $17 \%$ & 47 & $47 \%$ & 31 & $31 \%$ & 4 & $4 \%$ & 0 & $0 \%$ & 99 \\
\hline 3 & Fasilitas3 & 19 & $19 \%$ & 30 & $30 \%$ & 36 & $36 \%$ & 14 & $14 \%$ & 0 & $0 \%$ & 99 \\
\hline 4 & Fasilitas4 & 21 & $21 \%$ & 37 & $37 \%$ & 34 & $34 \%$ & 7 & $7 \%$ & 0 & $0 \%$ & 99 \\
\hline 5 & Fasilitas5 & 13 & $13 \%$ & 24 & $24 \%$ & 61 & $61 \%$ & 1 & $1 \%$ & 0 & $0 \%$ & 99 \\
\hline 6 & Fasilitas6 & 10 & $10 \%$ & 40 & $40 \%$ & 38 & $38 \%$ & 11 & $11 \%$ & 0 & $0 \%$ & 99 \\
\hline 7 & Fasilitas7 & 19 & $19 \%$ & 33 & $33 \%$ & 39 & $39 \%$ & 8 & $8 \%$ & 0 & $0 \%$ & 99 \\
\hline 8 & Fasilitas8 & 6 & $6 \%$ & 24 & $24 \%$ & 61 & $61 \%$ & 8 & $8 \%$ & 0 & $0 \%$ & 99 \\
\hline 9 & Fasilitas9 & 10 & $10 \%$ & 33 & $33 \%$ & 41 & $41 \%$ & 15 & $15 \%$ & 0 & $0 \%$ & 99 \\
\hline 10 & Fasilitas10 & 15 & $15 \%$ & 37 & $37 \%$ & 42 & $42 \%$ & 5 & $5 \%$ & 0 & $0 \%$ & 99 \\
\hline 11 & Fasilitas11 & 14 & $14 \%$ & 47 & $47 \%$ & 33 & $33 \%$ & 5 & $5 \%$ & 0 & $0 \%$ & 99 \\
\hline 12 & Fasilitas12 & 11 & $11 \%$ & 41 & $41 \%$ & 34 & $34 \%$ & 13 & $13 \%$ & 0 & $0 \%$ & 99 \\
\hline & Rata-rata & & $14 \%$ & & $36 \%$ & & $41 \%$ & & $8 \%$ & & $0 \%$ & \\
\hline
\end{tabular}

Pada tabel 1 di atas terihat bahwa yang menjawab sangat setuju sebanyak 14\%, yang menjawab setuju sebanyak $36 \%$, sedangkan responden yang menjawab cukup setuju sebanyak $41 \%$ dan yang menjawab tidak setuju sebanyak $8 \%$ dan yang menjawab sangat tidak setuju sebanyak $0 \%$. 
Deskripsi data variabel Kepuasan Pengunjung

Tabel 2 Rekapitulasi jawaban responden variabel Kepuasan Pengunjung (Y)

\begin{tabular}{|l|l|l|l|l|l|l|l|l|l|l|l|l|}
\hline \multirow{2}{*}{ No } & \multirow{2}{*}{ Pernyataan } & \multicolumn{2}{|c|}{ SS } & \multicolumn{2}{|c|}{ S } & \multicolumn{2}{|c|}{ CS } & \multicolumn{2}{|c|}{ TS } & \multicolumn{2}{|c|}{ STS } & \multirow{2}{*}{ Jlh } \\
\cline { 3 - 11 } & & $\mathrm{F}$ & $\%$ & $\mathrm{~F}$ & $\%$ & $\mathrm{~F}$ & $\%$ & $\mathrm{~F}$ & $\%$ & $\mathrm{~F}$ & $\%$ & \\
\hline 1 & Kepuasan Pengunjung1 & 18 & $18 \%$ & 32 & $32 \%$ & 44 & $44 \%$ & 5 & $5 \%$ & 0 & $0 \%$ & 99 \\
\hline 2 & Kepuasan Pengunjung2 & 7 & $7 \%$ & 24 & $24 \%$ & 45 & $45 \%$ & 23 & $23 \%$ & 0 & $0 \%$ & 99 \\
\hline 3 & Kepuasan Pengunjung3 & 3 & $3 \%$ & 27 & $27 \%$ & 53 & $53 \%$ & 17 & $17 \%$ & 0 & $0 \%$ & 99 \\
\hline 4 & Kepuasan Pengunjung4 & 10 & $10 \%$ & 25 & $25 \%$ & 49 & $49 \%$ & 15 & $15 \%$ & 0 & $0 \%$ & 99 \\
\hline 5 & Kepuasan Pengunjung5 & 17 & $17 \%$ & 37 & $37 \%$ & 41 & $41 \%$ & 4 & $4 \%$ & 0 & $0 \%$ & 99 \\
\hline 6 & Kepuasan Pengunjung6 & 3 & $3 \%$ & 33 & $33 \%$ & 54 & $54 \%$ & 10 & $10 \%$ & 0 & $0 \%$ & 99 \\
\hline 7 & Kepuasan Pengunjung7 & 1 & $1 \%$ & 20 & $20 \%$ & 32 & $32 \%$ & 42 & $42 \%$ & 4 & $4 \%$ & 99 \\
\hline 8 & Kepuasan Pengunjung8 & 1 & $1 \%$ & 30 & $30 \%$ & 26 & $26 \%$ & 38 & $38 \%$ & 4 & $4 \%$ & 99 \\
\hline 9 & Kepuasan Pengunjung9 & 26 & $26 \%$ & 43 & $43 \%$ & 30 & $30 \%$ & 0 & $0 \%$ & 0 & $0 \%$ & 99 \\
\hline 10 & Kepuasan Pengunjung10 & 29 & $29 \%$ & 42 & $42 \%$ & 28 & $28 \%$ & 0 & $0 \%$ & 0 & $0 \%$ & 99 \\
\hline & Rata-rata & & $12 \%$ & & $32 \%$ & & $40 \%$ & & $16 \%$ & & $1 \%$ & \\
\hline
\end{tabular}

Dari tabel di atas terlihat bahwa yang menjawab sangat setuju sebanyak 12\%, yang menjawab setuju $32 \%$, sedangkan responden yang menjawab cukup setuju $40 \%$ dan yang menjawab tidak setuju $16 \%$ dan yang menjawab sangat tidak setuju sebanyak $1 \%$.

\section{Uji Validitas dan Reabilitas}

Uji validitas digunakan untuk melihat ketepatan instrumen yang digunakan dalam penelitian. Instrumen dikatakan valid jika nilai $r_{\text {hitung }}>r_{\text {tabel. }}$. Hasil validitas dari instrumen variabel penelitian adalah sebagai berikut:

Tabel 3 Validitas instrumen variabel Fasilitas (X)

\begin{tabular}{|l|c|c|c|}
\hline \multirow{2}{*}{ Instrumen } & \multicolumn{2}{|c|}{ Nilai Validitas } & \multirow{2}{*}{ Kesimpulan } \\
\cline { 2 - 2 } & rhitung & rtabel & \\
\hline Fasilitas1 & .340 & & Valid \\
\hline Fasilitas2 & .235 & & Valid \\
\hline Fasilitas3 & .367 & \multirow{4}{*}{0} & Valid \\
\hline Fasilitas4 & .443 & Valid \\
\hline Fasilitas5 & .433 & Valid \\
\hline Fasilitas6 & .428 & Valid \\
\hline Fasilitas7 & .435 & & Valid \\
\hline Fasilitas8 & .500 & & Valid \\
\hline Fasilitas9 & .419 & & Valid \\
\hline Fasilitas10 & .314 & & Valid \\
\hline Fasilitas11 & .405 & & Valid \\
\hline Fasilitas12 & .276 & & Valid \\
& &
\end{tabular}

Dari tabel terlihat bahwa hasil pengujian masing-masing instrument variabel fasilitas (x) memiliki r-hitung $>0.166$, dengan demikian dapat disimpulkan bahwa seluruh instrumen pernyataan dari variabel fasilitas yang digunakan valid.

Tabel 4 Validitas instrumen variabel Kepuasan Pengunjung (Y)

\begin{tabular}{|c|c|c|c|}
\hline \multirow{2}{*}{ Instrumen } & \multicolumn{2}{|c|}{ Nilai Validitas } & Kesimpulan \\
\cline { 2 - 2 } & rhitung & rtabel & \\
\hline Kepuasan Pengunjung 1 & 0.366 & \multirow{4}{*}{0} & Valid \\
\hline Kepuasan Pengunjung 2 & 0.581 & Valid \\
\hline Kepuasan Pengunjung 3 & 0.242 & \multirow{2}{*}{0.166} & Valid \\
\hline Kepuasan Pengunjung 4 & 0.495 & & Valid \\
\hline Kepuasan Pengunjung 5 & 0.488 & & Valid \\
\hline
\end{tabular}




\begin{tabular}{|c|c|c|} 
Kepuasan Pengunjung 6 & 0.550 & Valid \\
\hline Kepuasan Pengunjung 7 & 0.511 \\
\hline Kepuasan Pengunjung 8 & 0.524 \\
\hline Kepuasan Pengunjung 9 & 0.337 \\
\hline Kepuasan Pengunjung 10 & 0.260 & Valid \\
& & Valid \\
\cline { 2 - 2 } & & Valid \\
\hline
\end{tabular}

Dari tabel terlihat bahwa hasil pengujian masing-masing instrument variabel kepuasan pengunjung (y) memiliki r-hitung $>0.166$, dengan demikian dapat disimpulkan bahwa seluruh instrument pernyataan dari variabel kepuasan pengunjung yang digunakan valid.

Uji realibilitas dilakukan untuk menjamin instrument yang digunakan merupakan instrumen yang handal, konsisten dan stabil jika digunakan secara berulang-ulang pada waktu yang berbedabeda. Instrument dikatakan reliabel jika nilai cronbach alfa hitung > cronbach alfa toleransi (0.6). Hasil pengujian reliabilitas terlihat seperti berikut ini:

Tabel 5 Hasil Reabilitas Instrumen Penelitian

\begin{tabular}{|r|l|c|c|}
\hline No & \multicolumn{1}{|c|}{ Variabel } & $\begin{array}{c}\text { Nilai } \\
\text { crombach's } \\
\text { alfa }\end{array}$ & Kesimpulan \\
\hline 1 & Fasilitas (x) & 0.747 & Reliabel \\
\hline 2 & Kepuasan pengunjung (y) & 0.771 & Reliabel \\
\hline
\end{tabular}

Hasil uji reliabilitas menunjukkan bahwa nilai Cronbach's alfa seluruh variabel lebih besar dari 0,6. Maka dapat disimpulkan bahwa kuesioner penelitian ini reliabel.

\section{Hasil Uji Regresi Linear Sederhana}

Pengujian ini dilakukan untuk mengetahui pengaruh fasilitas terhadap kepuasan pengunjung pada Hairos Water Park. Berikut ini tabel hasil pengujian regresi linear sederhana pada masingmasing variabel yaitu:

Tabel 6 Hasil Uji Regresi Linear Sederhana

Coefficients ${ }^{\mathrm{a}}$

\begin{tabular}{|c|c|c|c|c|c|c|}
\hline \multirow{2}{*}{\multicolumn{2}{|c|}{ Model }} & \multicolumn{2}{|c|}{$\begin{array}{l}\text { Unstandardized } \\
\text { Coefficients }\end{array}$} & \multirow{2}{*}{$\begin{array}{c}\begin{array}{c}\text { Standardized } \\
\text { Coefficients }\end{array} \\
\text { Beta }\end{array}$} & \multirow[b]{2}{*}{$\mathrm{t}$} & \multirow[b]{2}{*}{ Sig. } \\
\hline & & $\mathrm{B}$ & Std. Error & & & \\
\hline \multirow[t]{2}{*}{1} & (Constant) & 36.015 & 3.971 & & 9.069 & .000 \\
\hline & Fasilitas (x) & -.052 & .092 & -.058 & -.570 & .570 \\
\hline
\end{tabular}

a. Dependent Variable: Kepuasanpengunjung (y)

Berdasarkan hasil pengujian diatas, maka diperoleh persamaan regresi linear sederhana sebagai berikut:

$$
\mathrm{Y}=36.015+(-0.052 \mathrm{X})
$$

Pada model regresi linear sederhana diperoleh nilai constanta kepuasan pengunjung sebesar 36.015 artinya jika nilai variabel bebas (X) nilainya 0 , maka variabel terikat (Y) nilainya sebesar 36.015. Koefisien regresi variabel bebas bernilai negatif, artinya kepuasan pengunjung pada Hairos Water Park tidak dipengaruhi oleh fasilitas.

\section{Pengujian Hipotesis}

a. Koefisien Determinasi $\left(R^{2}\right)$

Koefisien determinasi bertujuan untuk mengukur berapa besar kemampuan variabel bebas dalam menerangkan variabel terikat. Nilai koefisien determinasi dapat dilihat pada tabel berikut:

Tabel 7 Hasil Uji Koefisien Determinasi $\left(R^{2}\right)$ 


\begin{tabular}{|l|c|r|r|r|}
\hline & & & Model Summary \\
Model & $\mathrm{R}$ & R Square & $\begin{array}{c}\text { Adjusted R } \\
\text { Square }\end{array}$ & $\begin{array}{c}\text { Std. Error of } \\
\text { the Estimate }\end{array}$ \\
\hline 1 & $.058^{\mathrm{a}}$ & .003 & -.007 & 4.66462 \\
\hline
\end{tabular}

a. Predictors: (Constant), Fasilitas (x)

Nilai koefisien determinasi yang diperoleh sebesar 0.003 atau $0.3 \%$ menunjukkan bahwa variabel fasilitas menjelaskan variasi yang terjadi pada kepuasan pada Hairos Water Park, sedangkan sisanya $99.7 \%$ dijelaskan oleh variabel lain yang tidak diteliti dalam penelitian ini seperti kualitas pelayanan, kualitas produk dan lainnya.

b. Uji Parsial (uji t)

Uji parsial (uji t) bertujuan untuk melihat pengaruh fasilitas terhadap kepuasan pengunjung, dengan kriteria:

1. jika $t_{\text {hitung }} \leq t_{\text {tabel }}$, maka $\mathrm{H}_{0}$ diterima $\mathrm{H}_{1}$ ditolak, artinya secara parsial penelitian tidak berpengaruh.

2. jika $t_{\text {hitung }}>t_{\text {tabel}}$, maka $\mathrm{H}_{0}$ ditolak $\mathrm{H}_{1}$ diterima, artinya secara parsial dan penelitian berpengaruh atau ada pengaruh.

Tabel 8 Hasil Uji Parsial (uji t)

Coefficients $^{\mathrm{a}}$

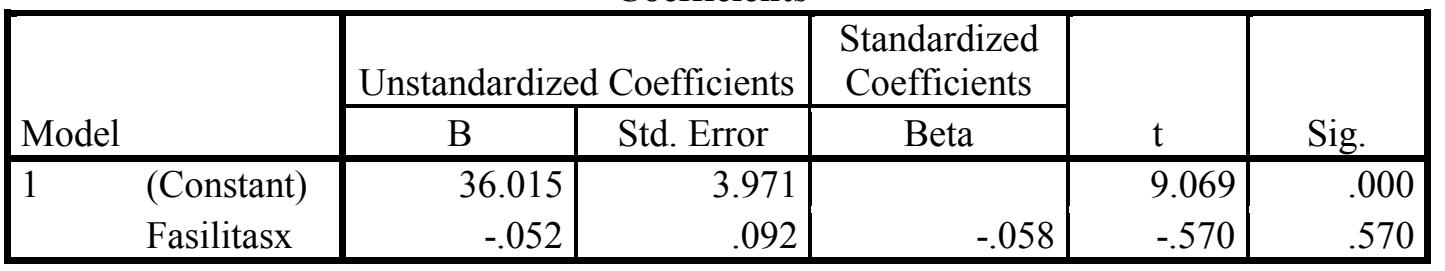

a. Dependent Variable: Kepuasan pengunjung (y)

Berdasarkan tabel tersebut dapat dilihat bahwa nilai $t_{\text {hitung }}$ untuk variabel fasilitas $-0.570 \leq$ $\mathrm{t}_{\text {tabel }} 1.655$ dan nilai signifikan $0.570>$ dari alpha 0.1 , maka $\mathrm{H}_{0}$ ditolak dan $\mathrm{H}_{1}$ ditolak, dengan demikian secara parsial variabel tidak berpengaruh terhadap kepuasan pengunjung.

\section{Pembahasan}

Hasil pengujian hipotesis pertama menunjukkan bahwa variabel fasilitas mampu menjelaskan variasi yang terjadi pada kepuasan pengunjung di Hairos Water Park, ini dibuktikan dengan nilai koefisien determinasi $\left(\mathrm{R}^{2}\right)$ yang diperoleh sebesar 0.003 atau $0.3 \%$, sedangkan sisanya sebesar $99.7 \%$ dijelaskan oleh variabel lain yang tidak diteliti dalam penelitian ini.

Hasil pengujian hipotetsis kedua bahwa secara parsial fasilitas tidak berpengaruh pada kepuasan pengunjung. Hasil penelitian ini tidak sesuai dengan penelitian yang dilakukan Penelitian yang dilakukan oleh Amaliawati (2015) yang berjudul Pengaruh Fasilitas dan Harga Tiket Terhadap Kepuasan Pengunjung Obyek Wisata Umbul Penging, hasil penelitiannya menunjukkan bahwa fasilitas berpengaruh positif terhadap kepuasan pengunjung objek wisata Umbul Penggin Surakarta.

\section{KESIMPULAN}

Berdasarkan hasil penelitian dan pembahasan pada bab sebelumnya, maka dapat disimpulkan bahwa Secara parsial variabel fasilitas tidak berpengaruh dan tidak signifikan terhadap kepuasan pengunjung pada Hairos Water Park. 


\section{REFERENCES}

Amaliawati, S. (2015). Pengaruh Fasilitas dan Harga Tiket Terhadap Kepuasan Pengunjung Obyek Wisata Umbul Penging. Universitas Muhammadiyah Surakarta.

Hasan, A. (2015). Tourism Marketing (1th ed.). Yogyakarta: CAPS.

Lumentut, F. L,. \& Palandeng, I. D. (2014). Fasilitas, Servicescap dan Kualitas Pelayanan Pengaruhnya Terhadap Kepuasan Konsumen MCDonal's Manado. EMBA, 2(3), 126-136.

Mongkaren, S. (2013). Fasilitas dan Kualitas Pelayanan Pengaruhnya Terhadap Kepuasan Pengguna Jasa Rumah Sakit Advent Manado. Jurnal EMBA, 1(4), 493-503.

Rosita., Marhanah, S., \& Wahadi, W. H. (2016). Pengaruh Fasilitas Wisata dan Kualitas Pelayanan Terhadap Kepuasan Pengunjung di Taman Margasatwa Ragunan Jakarta. Jurnal Manajemen Resort Dan Leisure, 13(1), 61-72.

Sofianita, A. F. (2014).Pengaruh Kualitas Pelayanan dan Fasilitas Terhadap Kepuasan Mahasiswa IAIN Walisongo di Perpustakaan IAIN Walisongo, Semarang. Universitas IAIN Walisongo Semarang.

Stevianus. (2014). Pengaruh Atraksi Wisata, Fasilitas dan Kualitas Pelyanan Terhadap Kepuasan Pengunjung di Taman Margasatwa Ragunan Jakarta. Jurnal Ekonomi Bisnis, 19(3), 39-48.

Sugiyono. (2012). Metode Penelitian Bisnis (Pendekatan Kuantitatif, Kualitatif, dan R\&D). Bandung: Alfabeta.

Sulistiyana, R. T., Hamid, D., \& Azizah, D. F. (2015). Pengaruh Fasilitas Wisata dan Harga Terhadap Kepuasan Konsumen (Studi pada Museum Satwa). Jurnal Admisnistrasi Bisnis, 25(1), 1-9.

Tjiptono, F., \& Chandra, G. (2016). Service, Quality dan Setatisfaction (4th ed.). Yogyakarta: Andi.

Toriq, M. (2014). Pengaruh Fasilitas dan Kualitas Terhadap Kepuasan Pelanggan pada SPBU Pertamina 54.612.64 di Sidoarjo. Jurnal Ilmu \& Riset Manajemen, 3(8), 1-16.

Tumvila, D. (2015). Pengaruh Kualitas pelayanan, Fasilitas, dan Persepsi Harga Terhadap Kepuasan Konsumen Bus Harapan Jaya di Tulungagung, kediri. Universitas Nusantara PGRI Kediri.

Utama, I. G. agus R. (2017). Pemasaran Pariwisata (1th ed.). Yogyakarta: Andi. 